\title{
Acknowledgments
}

This project took a long time. I want to make this clear. By describing the path from initial idea to the book in your hand, my hope is that a graduate student realizes the numerous people involved in writing a "solo" project and how research projects require numerous "back to the drawing board" moments.

The original data on failed military alliance treaty negotiations were collected as part of my dissertation at the University of Michigan. My dissertation was not about military alliances per se or even about military negotiations. Instead, it was a series of connected papers evaluating the effectiveness of issue linkage as a means of reaching and maintaining agreements. I was inspired to pursue this topic after discovering the Alliance Treaty Obligation and Provision (ATOP) data in a course with Barabara Koremenos. Within those data, I found that some alliances had economic cooperation provisions. William Roberts Clark then helped me to think through the reasons states would find economics a useful instrument and James Morrow guided how I conceived of issue linkage within the context of alliances. Walter Mebane then led me through the painstaking process of figuring out how to evaluate the effectiveness of issue linkage offers. I realized that this required data on successful and failed negotiations. While evidence of the former was located in ATOP, the latter required creating a wholly new dataset. That is when, after a suggestion by Morrow, I began reading diplomatic histories with the hope of identifying failed negotiations.

I eventually submitted the core chapter of the dissertation to the journal International Organization. During the review process, an anonymous referee suggested that a future project could explore alliance treaty negotiation failure itself (not solely as a means of exploring issue linkages). Once that paper was accepted at International Organization and the other papers of my dissertation were published, I set out to write the paper suggested by that reviewer.

I worked on the paper during my first three years as an assistant professor at Rutgers University. I completely rewrote the paper on numerous occasions, but none of these drafts was ever submitted to a journal. Each new draft was leading to either a methodological or a theoretical dead end. I continued to have difficulty making the paper, for lack of better terminology, "work." Mind you, this road block was all on me. I was receiving immensely helpful suggestions from numerous individuals, namely, Jeff Arnold, Leonardo Baccini, Brett Benson, Benjamin 
Fordham, Mareike Kleine, Yonatan Lupu, Michael McKoy, James Ashley Morrison, Shawn Ramirez, and Eric Reinhardt. In particular, Ashley Leeds, Dan Reiter, and Jack Levy (my senior colleague at Rutgers) offered extensive suggestions that encouraged me to continue working on the project.

Keren Yarhi-Milo eventually helped me turn the corner and produce the manuscript before you. After reading a draft of the paper, she suggested that I needed to make the paper a full-length book in order to do justice to the argument and evidence. That's when things clicked. I was coming to this realization on my own, as my inability to fit my argument and evidence into a paper seemed to be my road block. Keren's suggestion convinced me that writing a book manuscript was the right approach. Sure enough, intellectually committing to a book gave my ideas "room to breathe" and the page space to say exactly what I wanted to say.

I then moved to the University of Chicago, where my new colleagues encouraged me to focus on the manuscript. After completing a first full draft of the manuscript, Ashley and Keren, along with Scott Wolford and Timothy Crawford, came to Chicago to read and critique it. Additionally, numerous members of Chicago's political science department came to the workshop to offer suggestions and comments. John J. Mearsheimer generously chaired the all-day workshop. He went beyond simply keeping the trains running on time by asking follow-up questions of a commenter in order to clarify his or her critique or comment (and at one point summarized several lines of argument by writing them on the board). I then received additional comments (and a three hour "debrief" over coffee) from Dan Reiter. After reflecting on all these comments, I finally knew the direction to take the argument.

I then spent the next year rewriting and reorganizing the manuscript. My colleagues at Chicago continued to help me think through and refine my ideas (helped by my decision to leave a drawing of the theory's two-by-two on a white board in my office so as to facilitate on-the-spot brainstorming whenever someone stopped in). In addition to John, my international relations colleagues-Robert Pape, Paul Staniland, Austin Carson, Robert Gulotty, and Charles Lipson-were crucial in helping me to solidify the new direction of the manuscript. Paul was especially supportive with navigating the review process with Cornell. Speaking of the review process, Roger Haydon was masterful in guiding me through it. Whether helping me to craft the (numerous) response memorandums or managing the reviewers, Roger was instrumental in seeing the manuscript to the finish line. The anonymous reviewers offered immensely helpful comments, with one of the reviewers being especially thoughtful and constructive. This reviewer championed the project (while 
also pushing me to make much needed changes), and I am grateful for his or her support (without which, I'm not sure the book would have been accepted).

I am proud of this book. But as the above narrative reveals, this was not a work in isolation. Academia is a communal enterprise. It requires having others see and respond to your work (and lend a helping hand). Even a "solo" project is still a team effort. 



\section{ARGUING ABOUT ALLIANCES}


